\title{
O Conceito de Resistência na Psicoterapia Grupo-Analítica: Repensando um Caminho ${ }^{1}$
}

\author{
Jorge Ponciano Ribeiro \\ Universidade de Brasília
}

\begin{abstract}
RESUMO - O autor faz um estudo da resistência em grupo baseado na obra de Siegmund Heinrich Foulkes, fundador da Psicoterapia Grupo Analítica. Foulkes utilizava os conceitos da Psicologia da Gestalt e da Teoria do Campo para fazer compreender o processo de mudança nos seus grupos, embora essas referências passassem desapercebidas, talvez pela dificuldade epistemológica que ele encontrava em combinar Psicanálise e essas teorias. O autor retoma os rastros de Foulkes e desenvolve, a partir dos conceitos de figura e fundo e aqui e agora, uma visão diferente na perspectiva foulkesiana, acenada por ele, mas não desenvolvida. Foulkes tem também uma linguagem fenomenológica que o autor procura explorar.
\end{abstract}

Palavras-chave: resistência; psicoterapia grupo analítica; Foulkes.

\section{The Concept of Resistance in the Group-Analytic Psychotherapy: Rethinking a Path}

\begin{abstract}
The author makes a study of the resistance in group based on the work of Siegmund Heinrich Foulkes, founder of the Group-Analytic Psychotherapy. Foulkes used the concepts of the Psychology of Gestalt and of the Theory of the Field to understand the change process' in their groups, although those references passed unnoticed, maybe for the epistemological difficulty that he found in combining psychoanalysis and those theories. The author retakes the traces of Foulkes and develops, beginning with concepts of here and now, and figure and group a different vision in the Foulkesian perspective, waived by him, but not developed. Foulkes also has a phenomenological language which the author attempts to explore.
\end{abstract}

Key words: resistance; group-analytic psychotherapy; Foulkes.

A resistência tem sido considerada como um obstáculo ao processo de cura. Ela se tornou a frente de combate de quase todas as terapias individuais e de grupo, nela se concentrando os esforços do analista. Estamos colocando o problema de abordar a resistência como figura e/ou fundo no aqui e agora do processo grupal, segundo pressupostos foulkesianos. Foulkes faz freqüentemente referência à teoria gestáltica para explicar fenômenos grupais.

Nossa proposta de trabalho é: sem esquecer o aspecto da interpretação analítica da resistência em grupo, estudar como entender e como trabalhar a resistências em grupo analítico, sobretudo com base em dois conceitos da teoria gestáltica: figura e fundo e aqui e agora. $\mathrm{Na}$ realidade, o que queremos explorar é a novidade da visão de Foulkes no que concerne ao processo do grupo.

Ele utiliza, sobretudo na sua última obra, conceitos da Teoria do Campo da Psicologia da Gestalt para fazer compreender a riqueza do processo grupal. Mas mais do que isso, ele insiste na percepção do imediato, do fenômeno, da realidade como se apresenta ao observador e da necessidade de se deixar influenciar pelas necessidades da realidade, da vida, sob pena de não se poder compreendê-la.

É nesse contexto que queremos lembrar o lado existencial-fenomenológico de sua obra.

1 Reedição de texto publicado em 1989, no volume 5 número 1, na revista Psicologia: Teoria e Pesquisa (pp. 123-135).

\section{Definição do problema}

Resistência é usualmente definida como tudo que se opõe, no paciente, ao acesso a seu inconsciente por palavras ou atos. Estendendo essa definição ao grupo, podemos focalizar dois processos básicos de resistência: resistência do grupo e resistência no grupo. A resistência do grupo é um processo que opera mais a nível pré-consciente ou consciente e pode incluir resistência ao próprio tratamento. Pode manifestar-se sob diversas formas, como oposição ao analista, ao horário, à técnica, ao pagamento, etc. É uma resistência aqui, em termos de rede de comunicação, e de figura, segundo a teoria gestáltica, usando a terminologia foulkesiana (Foulkes, 1948).

A resistência $\mathrm{em}$ grupo supõe processos mais profundos, porque ela envolve oposição às descobertas que podem ser desagradáveis e, dando consciência ao indivíduo e ao grupo, pode levá-los à necessidade de opções novas. Esse movimento é mais característico do grupo como um todo e, por conseguinte, é um processo mais complexo dinamicamente. É uma resistência no plano de matriz e fundo, usando ainda a terminologia foulkesiana.

A localização da resistência revela o segredo da neurose grupal e, ao mesmo tempo, cria situação para agir aqui e agora na dinâmica do comportamento grupal, no sentido de que o exercício espontâneo da comunicação favorece o desenvolvimento de forma mais articulada de expressão: do sintoma de conversão se chega à linguagem. É o que Foulkes (1967) chama de tradução. 
A resistência pode ser detectada na variedade das configurações da comunicação. Ela é a figura de um processo que, na sua totalidade, compreende o grupo como um todo. Nesse contexto, a interpretação tem sentindo quando parte para entender e fazer entender o fundo, que é o lugar onde os significados ocultos têm sentindo. É pela interpretação que a figura se transforma em fundo e o fundo em figura.

Foulkes continua:

É claro que entendemos aqui a referência à idéia de figura e fundo da Gestalt como conceitos inseparáveis. Na minha opinião esta não é meramente um modo de percepção, mas isto corresponde à atual compreensão da psicodinâmica da situação grupal (1975, p. 131).

Freud fala de camadas concêntricas ao redor de um núcleo central patogênico e que quanto mais a ação terapêutica se aproxima desse núcleo, mais a resistência cresce.

Partindo do conceito foulkesiano de que o grupo constitui uma unidade anterior ao indivíduo, parece que podemos afirmar que a resistência em um grupo de grupo-análise constitui uma entidade à parte, independentemente da soma, mesmo qualitativa, das resistências de cada um, ou seja, o grupo analítico forma a sua própria resistência.

Usando a terminologia freudiana, parece que podemos dizer que, no grupo analítico, as camadas concêntricas são formadas pelas resistências individuais, e que o núcleo patogênico é a resistência desenvolvida como um todo. As camadas concêntricas estão para a figura e a rede de comunicação, assim como o núcleo central está para o fundo e a matriz.

Em termos metodológicos, a interpretação da resistência pode dirigir-se tanto à figura quanto ao fundo, mas a interpretação do fundo, ou seja, do núcleo central, é um processo mais aqui e agora. Analisar a resistência grupal significa clarear as resistências.

É importante observar que a noção de figura e fundo não está necessariamente ligada à profundidade do material apresentado. Quando se diz que o núcleo central patogênico de um grupo é o fundo, não se está dizendo que os processos que ele encerra são mais profundos e complexos do que aqueles das camadas concêntricas representadas pelas defesas individuais.

Considerando que o núcleo central patogênico, que eu pessoalmente chamo de centro de convergência neurótica, está em segundo plano, a análise da resistência do grupo como um todo se torna mais ameaçadora, porque a resistência aumenta na razão em que o trabalho da interpretação ou análise se aproxima do ponto em que a energia grupal se percebe sem forças contra as representações penosas.

Eu não digo que a resistência grupal é causada apenas pela matriz ou fundo, pois parece que a matriz, na sua dinamicidade, não envolve necessariamente resistência, pois, sendo a matriz uma força dinâmica, ela deve abrir caminho para o inconsciente se soltar. A resistência é provocada pelas camadas concêntricas ou eixos psíquicos, ou seja, pelos problemas anteriores dos indivíduos no grupo, os quais anteriormente provocaram a repressão, que impede o inconsciente grupal de tornar-se consciente.
Como na análise individual, também na análise de grupo as resistências do ego ou do grupo não são suficientes para explicar as dificuldades encontradas na progressão e acabamento do trabalho analítico.

$\mathrm{Na}$ verdade, continuando o pensamento freudiano, podemos afirmar que, afastadas as resistências do eu e do superego, algumas pessoas continuam entregues a uma ininterrupta repetição das mesmas representações. E que, afastadas as resistências do ego e superego, ao invés de acontecer uma libertação automática da pressão, parece que se deu uma chicotada na compulsão à repetição e que, com o enfraquecimento das defesas do eu, o id entre em plena ação.

Deixando de lado uma discussão teórica a respeito do id e sua relação com pulsão, parece que podemos afirmar que o id é também algo corporal, corpóreo. Talvez possamos falar também de um id e pulsões grupais, o que nos leva ao conceito de resistência corporal, e nesse caso o id estará relacionado a dois tipos de resistência: a resistência como processo psicológico (fundo) e resistência como processo orgânico (figura).

Estamos habituados, em análise de grupo, a lidar com resistência psíquica, mas não com resistência orgânica ou corporal. Se prestarmos atenção à comunicação de um indivíduo, em análise individual ou grupal, podemos observar que o trabalho com um processo de resistência psíquica forte é freqüentemente seguido de manifestações somáticas, como alteração da respiração, batidas cardíacas, etc. Tais reações psicossomáticas ou neurovegetais são expressão de um sofrimento psíquico forte, quase sempre indicando que o indivíduo focou um ponto doloroso, difícil e do qual ele, normalmente, tem medo e foge.

Também não é raro que alguém no grupo esteja se colocando com grande sofrimento e que elementos do grupo estejam, quase que movidos por uma força comum, sentindo corporalmente o que o outro está sentindo: o grupo respira fundo, sua, o coração acelera. Chamo este processo de resistência orgânica porque, quando acontece, o grupo, geralmente está tratando de coisas difíceis e dolorosas e das quais tenta sistematicamente fugir.

É sabido que, quando a criança recebe muitas proibições dos pais, ela incorpora sentimentos e emoções que podem ser registrados muscularmente, ou seja, certas tensões musculares estão associadas a proibições antigas e, freqüentemente, quando se trabalham e se interpretam tensões musculares, surgem conteúdos traumáticos associados a comportamentos antigos dos pais.

O mal-estar físico é um aviso orgânico de que se está mexendo com conteúdos traumatizantes e é normal que as pessoas tenham medo de lidar com a consciência sensorial imediata, que os pode levar à consciência da própria realidade. A resistência que surge então em forma de medo, de ansiedade é, por outro lado, uma sabedoria do organismo aqui e agora.

A interpretação da resistência apenas em nível dinâmico deixa uma lacuna, porque não atinge a resistência a nível orgânico.

Se o grupo analítico é considerado como um organismo vivo e, se tudo que acontece a um membro diz respeito a todo o organismo, a interpretação da resistência individual 
em grupo ou do grupo como um todo não pode separar o aspecto dinâmico do orgânico da resistência.

Não se pode analisar o fundo - as resistência psíquicas - e esquecer a figura - a resistência orgânica - pois, como diz Foulkes, figura e fundo são inseparáveis.

\section{A resistência como processo}

A idéia fundamental da Teoria da Gestalt é que o modo de perceber um objeto é determinado pelo contexto ou configuração total em que esse objeto se encontra, ou seja, a percepção é determinada pela relação entre os elementos do campo perceptivo e não pelas características dos componentes individuais.

Daqui se seguem dois princípios fundamentais da Teoria do Campo Lewiniana:

1) o comportamento é uma função do campo existente no momento em que ele ocorre;

2) a análise começa com o exame da situação considerada como um todo e da qual são diferenciadas as partes componentes.

O conceito de espaço de vida pode ajudar-nos na compreensão desses processos. Segundo esse conceito, devemos começar do geral para o particular. O espaço de vida é o universo do objeto ou do indivíduo. Ele contém e compreende todos os fatos possíveis para determinar o comportamento do indivíduo em um dado ambiente psicológico e em um dado momento.

Tais princípios se correlacionam totalmente com três posições básicas de Foulkes:

1) o grupo deve ser visto como um todo;

2) grupo e paciente se revezam como figura e fundo;

3) a situação deve ser considerada no seu aqui e agora.

Segundo a lógica desses princípios, podemos rever a Teoria da Gestalt para aprofundar o conceito de resistência no grupo analítico.

Mais uma vez, podemos buscar a relação entre espaço de vida e matriz de grupo. Como o espaço de vida do indivíduo, também a matriz é algo dinâmico, geradora de novos processos, feita dos processos individuais e deles diferente qualitativamente. É ela que determina a natureza do grupo e seus processos. Já falamos que a matriz é fundo e agora dizemos que o espaço vital do grupo funciona, analogicamente, como fundo, no sentido de que, embora sempre presente, ele não é visivelmente atuante.

Ainda nesse contexto, podemos dizer que no grupo existem basicamente dois tipos de resistência:

1) resistência do indivíduo;

2) resistência do grupo.

Embora tudo que acontece no grupo diga respeito a todo o grupo, teoricamente podemos afirmar que existem resistências que são produto da realidade interna do indivíduo e que só post factum passam a fazer parte do espaço vital do grupo, incorporado à matriz.

Nesse caso, podemos ainda fazer uma observação ulterior, ou seja, que as resistências individuais no grupo analítico funcionam como figura, como expressão da rede de comunicação de cada indivíduo e que a resistência grupal, formando o espaço de vida, funciona como a matriz e fundo do grupo.
É altamente significativo o modo como as resistências individuais se relacionam com a resistência grupal. Até que ponto a expressão e a vivência de uma resistência são expressões da individualidade de alguém ou até que ponto ressoa a vivência transferencial grupal presente naquele momento? (Foulkes, 1967, 1975; Foulkes \& Anthony, 1957).

Usando ainda a terminologia gestáltica de sistema e fronteira, podemos dizer que o grupo forma um sistema completo ou organismo integrado e que cada componente do grupo, com suas resistências pessoais, forma um subsistema. Quando Foulkes diz que tudo que acontece no grupo diz respeito ao grupo como um todo está também usando o conceito de tensão, segundo o qual um estado de tensão em um sistema particular tende a igualar-se com a quantidade de tensão dos sistemas que o cercam, ou seja, o sistema tenta contaminar os outros sistemas para encontrar uma condição de equilíbrio razoável.

Assim como cada elemento novo, de fora para dentro, altera a matriz do grupo, assim também todo elemento novo que surge no grupo vem da matriz grupal. Nessa linha, podemos dizer que toda nova resistência altera o espaço de vida do grupo, dá nova característica à matriz e também que toda resistência analisada altera essa mesma rede, colocando o sistema geral em maior estado de equilíbrio. Isso significa que qualquer processo novo é o resultado da interação de processos diversos que concorrem para modificação do sistema de comunicação entre os membros do grupo.

Nesse sentido, uma das funções mais importantes do analista é a localização da resistência dentro de dois conceitos: configuração do distúrbio e processo de comunicação que a resistência envolve dentro do pressuposto foulkesiano de que

qualquer acontecimento no grupo, ainda que ele pareça envolver um ou dois membros tem uma configuração tal que envolve todo o grupo. Tal acontecimento é parte de uma 'gestalt' (configuração) da qual ele é uma figura (primeiro plano), enquanto o fundo (plano de trás) é manifestado no resto do grupo. (Foulkes \& Anthony, 1957, p. 237; 1967, p. 88).

Isso significa que o analista deve estar atento para perceber a situação do movimento grupal. Sua atenção livremente flutuante poderá perceber melhor onde se encontra a resistência, desde que ele se encontre pessoalmente engajado nessa troca de figura e fundo, que é um processo básico do grupo.

O processo de comunicação, no seu aspecto externo, funciona como figura. No seu aspecto interno, ou de fundo, leva à localização do distúrbio.

Aqui se coloca outro problema importante, isso é, o que se analisa: a comunicação ou o comunicado. Foulkes trabalha com o aqui e agora e, de outro lado, ele fala que figura e fundo são inseparáveis. O aqui e agora é mais direto, real, objetivo, fenomenológico. A figura é mais aqui, o fundo é mais lá.

Isso nos leva a duas modalidades de interpretação na obra de Foulkes:

1) a interpretação horizontal que parte do aqui e agora e termina no aqui e agora, é a interpretação do óbvio que, nem sempre por ser óbvio, é claro e evidente para o indivíduo ou o grupo. 
2) a interpretação vertical que, partindo da figura da comunicação, aqui e agora, se volta ao passado, vai ao fundo; presente simbolicamente na figura.

É o que Foulkes chama de interpretar ou separar os aspectos explícitos da comunicação ("interpretar no sentido usual e comum da palavra", Foulkes \& Anthony, 1957, p. 255).

Foulkes, falando da comunicação, faz diversas colocações que trazem conseqüências importantes para a nossa análise da resistência como processo de comunicação. Falando da percepção e compreensão do significado da comunicação, conclui:

Assim nos transportamos da teoria da relatividade para o campo psicológico, interpessoal. Na base de nossas premissas, nós podemos aceitar todas as contribuições como comunicações válidas... nós agora damos um passo de grande conseqüência no momento em que submetemos qualquer comunicação ao processo de interpretação... O conteúdo se refere a qualquer forma de expressão tanto verbal quanto não-verbal; interação se refere tanto à pessoa quanto aos processos mentais (Foulkes \& Anthony, 1957, p. 255; Foulkes, 1967, p. 88).

"E finalmente" que qualquer acontecimento no grupo é considerado como tendo seu significado dentro da total comunicação ("rede de comunicação e matriz") do grupo, ainda que freqüentemente se refira mais particularmente a um ou mais membros do grupo. Isso constitui a relação figura-fundo dentro do grupo (Foulkes \& Anthony, 1957; Foulkes, 1967). Se formas verbais e não-verbais são formas de comunicação e se submetemos todas as comunicações aos processos de interpretação quanto ao significado e interação, a resistência deve ser interpretada na sua totalidade no que diz respeito à pessoa física e aos seus processos mentais (Foulkes \& Anthony, 1957).

Se um perfume, um gesto, uma postura física são formas de comunicação, e se esses elementos podem ser formas de resistência, então a interpretação deve abranger as formas físicas, corporais da resistência, bem como os processos mentais do indivíduo e do grupo (Foulkes, 1967).

Tal pressuposto nos leva a outro conceito freqüente na obra de Foulkes: aqui e agora. O que significa interpretar ou lidar com uma resistência, aqui e agora, seja ela individual ou grupal? Tudo que fazemos, fazemos aqui e agora. Quando lembramos o passado ou pensamos no futuro nós o fazemos aqui e agora. Agora, portanto, é tudo que existe. Nesse sentido, embora não seja possível viver no aqui e agora, porque o agora existe de forma absoluta, nada existe, exceto o aqui e agora (Perls, 1969).

O trabalho da resistência deve ser visto e analisado dentro desse aqui e agora, visível e fenomenológico. Nessa dimensão, Foulkes fala da interpretação de aspectos externos da comunicação e Foulkes e Anthony dizem explicitamente:

A situação do grupo, por outro lado, pertence muito mais à vida real, no presente, ao aqui e agora, e aos problemas de ajustamento atual. Nós reconhecemos plenamente o fundo inconsciente destes problemas, mas a sua análise não é primariamente dirigida para a resolução dos conflitos infantis na transferência (1957, p. 62).
Tal pressuposto nos leva a considerar a resistência, na sua forma verbal ou não-verbal, no contexto direto da experiência do aqui e agora.

Foulkes repete inúmeras vezes que seu trabalho se desenvolve no aqui e agora. Citaremos algumas passagens significativas.

Referindo-se ao papel do terapeuta, fala que o terapeuta trabalha, aqui e agora, com as experiências emocionais do grupo, observando os motivos do que acontece em determinado momento no grupo que está diante de nós (Foulkes, 1967).

É bastante clara essa posição fenomenológica de Foulkes, a qual foi, cada vez mais, se acentuando no seu trabalho. A questão é combinar sua posição teórica de análise, portanto de uma visão psicodinâmica dos processos mentais, e seu pressuposto prático fenomenológico de trabalhar a realidade aqui e agora, como se apresenta com os processos emocionais do grupo que está aqui diante de nós (figura e fundo). Foulkes, na realidade, não aprofundou tal situação e acredito que, no seu livro teórico inacabado, isso deveria ser um tema obrigatório. Não apenas o terapeuta trabalha nesse enfoque existencial, fenomenológico, mas Foulkes diz que os membros do grupo estão interessados no imediato da situação, no aqui e agora, nas relações interpessoais atuais (Foulkes, 1967).

Esta se interessa, sobretudo, dos processos de adaptação que se desenvolvem no presente imediato, no aqui e agora, deixando um pouco no segundo plano a comunicação verbal, em relação à possibilidade de observar e de agir diretamente na situação terapêutica. A investigação aprofundada do desenvolvimento genético da personalidade, da situação edípica, da sexualidade pregenital permanecem no domínio da psicanálise (Foulkes, 1967, p. 100).

Nessa afirmação, Foulkes coloca três posições muito importantes:

1) sua técnica trabalha com o presente imediato, aqui e agora;

2) prefere observar e agir diretamente na situação terapêutica e dar maior valor à comunicação verbal;

3) a investigação aprofundada e sistemática do passado pertence à psicanálise.

Foulkes afirma que aqui e agora significa sublinhar o valor da experiência direta na situação terapêutica, e que isso é uma característica fundamental comum às psicoterapias existenciais e conclui: "Enfrentar os problemas das conseqüências deste fato, sobretudo para a psicanálise, me levaria muito longe" (Foulkes, 1967, p. 157).

Apesar de Foulkes não ter aprofundado tais consequiências, ele continuou colocando os pressupostos de uma visão fenomenológica da realidade grupal. Essa posição se torna bastante clara quando Foulkes diz explicitamente:

No conjunto, podemos dizer que o condutor caminha do que é manifesto para o que é latente, isto é, para o sentido oculto. Isto se refere não apenas ao que é dito, mas também ao como é dito, ao que acontece e porquê. Como para acontecimentos manifestos não se deve assumir que estes sejam entendidos ou mesmo observados de maneira errônea. 
Primeiro de tudo, deve existir uma clara consciência do "que", somente após isto se deve passar ao "como", "em que maneira”, "que implicações estão agindo"? Muitas interpretações serão necessárias para fazer cada um no grupo ver e concordar com as perguntas a estas questões. A questão do "porque" não significa apenas o porque primeiro, mas "porque" exatamente agora, "porque” exatamente deste modo, "porque" exatamente através dele ou dela, e assim por diante (Foulkes, 1975, p. 110).

Aquilo que Foulkes dizia ser uma característica fundamental da psicoterapia existencial trabalhando por meio do aqui e agora, torna-se, me parece, característica também do seu grupo, de acordo com uma análise aprofundada do texto acima citado (Foulkes, 1967).

Nesse texto estão presentes alguns conceitos básicos das linhas fenomenológicas e existencialistas:

1) Figura de fundo.

2) Aqui e agora, é o fenômeno.

3) Podemos acrescentar o sentido novo e operacional do "porquê". "Why does not only mean why ultimately, but why just now..." (Foulkes, 1975, p. 110).

Sabemos que não se pode excluir a interpretação histórica, mas a interpretação do aqui e agora, portanto mais direta, centrada no visível, na figura, no fenômeno que abrange o que naquele momento é presente, se torna a base do grupo de grupo-análise.

Tais pressupostos nos conduzem a uma visão mais integrada do trabalho da resistência no grupo foulkesiano.

\section{Resistência como ação}

As reflexões feitas até o momento nos colocam diante de um problema metodológico: como trabalhar com a resistência?

$\mathrm{O}$ conceito de figura e fundo associado ao de aqui e agora parecem estabelecer regras imediatas de condução do grupo. Aqui e agora é a totalidade presente, ou seja, tudo o que está acontecendo, que está sendo comunicado é objeto de interpretação. A resistência acontece de muitas formas, sobretudo em duas: palavra e ação.

Vejamos, porém, antes, um pouco da evolução do conceito de linguagem e comunicação em Foulkes.

$O$ instrumento fundamental da comunicação é a linguagem e a própria linguagem nasceu da necessidade de comunicar, nasceu desta força que impede os membros do grupo a se interagir. Quando nós selecionamos a linguagem antes que a ação como nosso instrumento escolhido de terapia em grupo, nós escolhemos o mais perfeito instrumento de comunicação que o grupo possui (Foulkes \& Anthony, 1957, p. 244).

Alguns anos depois, embora afirmando que a palavra é um meio de comunicação altamente especializado e superior a qualquer outro, Foulkes mostra-se decepcionado com a palavra ao dizer. "As palavras, de outra parte, são símbolos flexiveis e, embora possam esconder mais do que revelam, se adaptam particularmente bem à complexa estrutura da sociedade humana e servem para expressar uma imensa colocação emotiva" (Foulkes, 1967, p. 297).
Se as palavras podem esconder mais do que revelar, resta o aqui e agora total como meio de solucionar o impasse entre a palavra e a verdade. E quando Foulkes (1975) propõe que se examine o "what", o "how" e finalmente o "why", parece uma clara indicação a analisar o fenômeno total a agir diretamente no grupo, mais do que lidar com palavras. A palavra só é ineficaz para explicar o mecanismo da resistência. Não se pode trabalhar só na palavra do paciente ou do terapeuta, porque em ambos existe uma defasagem entre a comunicação e o comunicado.

$\mathrm{Na}$ análise da resistência, tem-se que olhar e observar as formas não-verbais de resistência, como formas de comunicação analógica. Se um perfume, uma postura, um choro, uma modificação psicossomática do organismo são formas de comunicação, o analista de grupo, que tem olhos para ver, não pode fazer de conta que nada está acontecendo e deixar passar em silêncio uma figura clara, um aqui e agora pleno de significado. Mais do que a palavra, o organismo revela, às vezes, a intensidade dos processos que a mente recusa e que o organismo, na sua sabedoria, não pode se proibir de expressar, porque o organismo não pensa, ele age, segue a lei da preferência. Se é bom para o organismo resistir, ele resiste. Quase sempre esses sintomas são um aviso de que o organismo está chegando ou já chegou à fronteira de sua resistência.

Ouvimos, às vezes, o paciente dizer: "meu coração está batendo forte e eu estou com medo de continuar falando". Se a interpretação da comunicação não for em cima desse aqui e agora orgânico, se ela não se ativer ao fenômeno, ou seja, se o terapeuta não tentar entender, compreender esse "what, how and why just now", dificilmente a interpretação será real e objetiva; poderá informar, mas não fará o paciente compreender e aprender a desfazer suas resistências.

Quando o terapeuta usa apenas a palavra como interpretação, mesmo que ele seja treinado para não misturar suas coisas com as do paciente, a interpretação não deixa de ser uma fantasia sua, porque parte dele e de seu mundo interior. Se ele parte, no entanto, de uma informação do óbvio (o coração bate, a respiração fica difícil), sua interpretação é sobre o óbvio e o óbvio é o aqui e agora, é a figura. Ele parte do ponto certo de informação, o paciente e seu corpo. Aí a probabilidade de errar na interpretação é mais difícil.

Estamos falando do trabalho com a resistência em termos individual, mas o mesmo se pode dizer para o grupo. O grupo assume, por vezes, formas de resistência psíquica e corporal.

A atenção do terapeuta não pode dirigir-se apenas ao conteúdo da comunicação verbal; se aqui e agora, ele pode estabelecer contato direto e imediato com as expressões nãoverbais do grupo. Se a comunicação do grupo é não-verbal, corpórea ou orgânica, e essa comunicação encerra elementos de resistência, ela é a figura, a interpretação deve partir do manifesto, do óbvio.

Nós sabemos que o corpo registra, "introjeta", tanto quanto a mente, processos traumatizantes passados e presentes. Nós sabemos que, quando se indaga a um paciente ou grupo como eles se sentem a respeito de uma postura, de uma tensão muscular, freqüentemente surgem conteúdos passados que impedem a comunicação verbal. O "porque" vem pelo "como" e, nesse caso, a análise se torna mais existencial, 
lançando luzes não apenas sobre o problema agora, mas sobre o problema num contexto da existência total.

Usando a terminologia gestática, a análise de um subsistema leva harmonia aos demais sistemas e, em termos foukesianos, a análise de um ponto nodal da rede leva harmonia a toda a matriz. O mesmo se pode dizer seguindo o caminho inverso, a análise da matriz - grupo como um todo - ou do sistema total leva harmonia aos pontos nodais, bem como aos subsistemas. Tal pressuposto parece mais evidente quando se trabalha no aqui e agora.

Trabalhar com a resistência psíquica (verbal) e corporal (comunicação não-verbal) do grupo ou de um elemento é uma forma mais dinâmica e integrada de atingir o grupo ou o indivíduo como um todo. Esquecer o corpo é dividir o processo.

A palavra continua sendo o instrumento normal do terapeuta que não trabalha o corpo. Trabalhar o corpo, porém, nesse contexto, é fazer com que o grupo e pacientes entrem em contato com seu corpo, com seu mal-estar físico, orgânico. É fazer com que eles procurem e encontrem, no corpo, o sentido e resposta para seus sintomas.

O analista, por seu lado, deve trabalhar na comunicação total, interpretando as palavras que explicam ou acompanham as emoções e sentimentos do paciente ou do grupo. Os sintomas físicos são linguagens de uma realidade interior desconhecida. Interpretar a linguagem verbal e a do corpo significa atingir o indivíduo ou o grupo como um todo. Significa devolver-lhes sua verdadeira expressão existencial.

Se a resistência for trabalhada no plano psíquico e orgânico ocorrerá a liberação automática da resistência total com o conseqüente desaparecimento da compulsão à repetição, pois, nesse caso, não haverá apenas um enfraquecimento das defesas do eu, que permite o id entrar em ação, como diz Glover, mas ocorrerá uma equilibração do organismo como um todo.

\section{Resistência como processo de cura}

A análise da resistência grupal ou individual é um dos pontos básicos das técnicas analíticas. A análise da resistência, no entanto, exige muito cuidado, porque ela nasce da sabedoria do organismo, na sua necessidade de se defender de um suposto mal maior. Freqüentemente a resistência mantém a pessoa, o organismo ou o grupo, em estado de equilíbrio, ainda que esse equilíbrio seja precário.

Precisamos pensar se a análise da resistência ou a sua ruptura são mais benéficas do que manter o status quo, sobretudo no caso da resistência individual.

$\mathrm{O}$ aparecimento de uma resistência grupal ou individual segue normalmente um complicado e, às vezes, longo caminho. Parece que ela não deveria ser destruída por um toque instantâneo de mágica. Quem não resiste não se cura. Grupo que não resiste não caminha, dá passos no mesmo lugar. Quando um grupo responde com "amém" a todas as colocações do analista, alguma coisa vai mal.

Se uma defesa é "momentaneamente" um bem encontrado, renunciá-la sem contradição, sem oposição, pode significar que o grupo perdeu sua autocrítica, sua auto-estima, sua capacidade de discriminação.
Quando, numa batalha, o inimigo simplesmente foge, se omite, a vitória do vencedor pode certamente ser posta em dúvida. Mas se ele caminha palmo a palmo, certamente o terreno conquistado é seu, porque, nesse caso, ele não apenas conhece o inimigo, mas também o terreno.

O mesmo acontece com o trabalho da resistência. Ela se transforma num instrumento de cura somente quando o paciente ou grupo combate para conservá-la, mas vão mudando na razão em que vão percebendo que suas posições são inadequadas e que mantê-las não os leva, de fato, a novas opções de vida.

É preciso estar atento ao grupo bonzinho, bem educado. Tal grupo está se encontrando, mas não fazendo terapia. Ainda aqui o analista, observando o aqui e agora, deve identificar como o comportamento verbal e não-verbal do grupo são contraditórios. A linguagem da resistência é normalmente seguida de tensão, ansiedade. Terapia sem tensão, sem ansiedade não é terapia. Sempre que percebermos tensão, ansiedade, podemos ter certeza de que se está lidando com conteúdos ameaçadores e profundos, ou seja, estamos na área de conflito. E esse é campo propício para as nossas intervenções.

\section{Conclusão}

Foulkes é, sem dúvida alguma, um pioneiro cuja obra, lamentavelmente, não pôde ser completada. Espírito aberto, Foulkes, embora mantendo sempre seu espírito analítico, incorporou, no seu sistema grupal, posições e conceitos cujas conseqüências não foram ainda suficientemente estudadas.

Freud, Norbert Elias, Kurt Lewin, Kurt Goldstein, Gustav Von Bergann estão presentes nos seus trabalhos, fazendo com que seu pensamento seja um pensamento flexível, prático e muito rico.

Nossa intenção é dar um passo no conhecimento das conseqüências das posições teóricas ensinadas por Foulkes.

Fica clara, nas entrelinhas de sua obra, sobretudo no seu último livro de 1975, a sensação de incompleto, de insatisfação por ver claro demais e se sentir amarrado ao peso de uma metodologia psicanalítica tradicional.

Em uma conversa com Foulkes em Londres, pouco antes de sua morte, ele me disse que continuava psicanalista ortodoxo quanto à terapia individual, mas que seus trabalhos com grupos encontraram sempre a oposição da Sociedade Psicanalítica de Londres, sobretudo nos tempos de Melanie Klein e Jones.

Esse trabalho de pesquisa quer, sobretudo, continuar levantando a ponta do véu que encobre um verdadeiro movimento de mudança na obra de Foulkes e que ele mesmo não teve tempo de completar.

A riqueza do pensamento foulkseinao reflete sua abertura ante todas as ciências das quais colheu elementos, transformando-os e iniciando um método de psicoterapia grupal, em um processo único de síntese criativa e pessoal (Ribeiro, 1981).

\section{Referências}

Foulkes, S. H. (1948). Introduction to group-analytic psychotherapy. London: Ed. Heinemann. 
Foulkes, S. H. \& Anthony, E. J. (1957). Group psychotherapy approach. Harmondsworth: Penguim Books.

Foulkes, S. H. (1967). Analisi terapeutica di grupoo. Torino: Ed.Boringhieri.

Foulkes, S. H. (1975). Group analytic psychotherapy. Method and principies, London: Gordon and Breach, Science Pub.
Perls, F. S. (1969). Gestalt Therapy verbatium. Lafayette: Real People Press.

Ribeiro, J. P. (1981). Psicoterapia grupo analítica. Abordagem foukiana: teoria e técnica. Petrópolis: Ed Vozes. 